\title{
Design of automatic moving wheelchair for physically challenged and patient in hospital
}

\begin{abstract}
Physically handicapped, old age and patients are difficult to move from one place to another place without help of others, because their physical body conditions needed some supporter to move from one place to another place. Even wheel chair help to overcome those problems, but it also requires one persons help for moving from one place to another place. Particularly in hospital shortage of nurses and helper for the patient are not able to move from one place to another place. Patients are totally depended. The Objective and purpose of this proposed system is to move the vehicle without depend on another with user friendly. The approach and methodology of the proposed system is micro-controller user to control the electric wheel chair. The micro-controller operation is based on acceleration sensor connected which is connected patient hand gloves, so patient doesn't feel any complicated to operate the electric wheel chair moment. The outcome of the proposed system is to operate very-well in both forward and reverse direction. In addition with, the proposed system connected with gear arrangement, with help of adjusting gear method one can control the vehicle. The value of the vehicle is more helpful for those who want to live their life independently.
\end{abstract}

Keywords: wheel chair, micro-controller, acceleration sensor, PMDC motor
Volume 6 Issue 4 - 2020

\section{R Arulmurugan}

Department of EE, Sanjivani College of Engineering, India

Correspondence: Professor, Department of Electrical Engineering, Sanjivani college of Engineering, India, Tel 919524396176,

Email arul.lect@gmail.com, arulmuruganelect@sanjivani.org.in

Received: September 29, 2020 | Published: November 30, 2020

\section{Introduction}

In the past decade more research has focused on electric vehicle and electric tricycle for physically challenged people, patient, and old age people. Particularly inside the house and hospital still everywhere conventional wheelchair moment vehicle are used. These wheelchair moments required one assistant. ${ }^{1-3}$ The assistance may be nurse, ward boy or someone close relative. Without support of them the wheelchair cannot moves from one place to another place. ${ }^{4-6}$ These assistant cants able to stay long duration with patients. The patient may feel guilty of getting help from other people. Due to these problems three-wheel petrol scooter came into the picture. These three-wheel scooter make good balance, but it costs more. It comes more than 40 thousand rupees. Further it requires fuel charge of 100 rupees for travel 30$50 \mathrm{kms}$. Those people poverty and below poverty line cannot afford it. The recent technology create spark on electric vehicle. ${ }^{7-10}$ The electric vehicle creates more advantages, such as it does not make any noise, pollution free, smooth start and stop system, but market exciting electric vehicle cost was high. It cannot afford by average and below average people. The same concept implements into the proposed electric vehicle-based wheelchair system. ${ }^{11,12}$ The approach and methods of this operation is like electric vehicle. Here we can apply the power through micro controller actuator or relay system.

\section{Methodology}

\section{Research design of the proposed system}

The proposed system is especially developed for the physically challenged people and patient. The system consists of the Permanent Magnet Direct Current (PMDC) motor. These motors operate on both forward and reverse direction based on the power supply, when power supply changes these motors it will rotate on reverse direction easily. The proposed system consists of following parts such as PMDC motor, battery system, and micro controller-based control system.

The motor operated through actuator. The actuator is nothing but conversion of electrical signal into mechanical signal. Here relay type of actuator is used. The relay gets the input signal from the microcontroller and produce the ON and OFF signal to device. Based on the signal commends the PMDC motor was operated, the power signal sends to the micro-controller. The micro-controller gives the command to the relay system. These commend based relay ON and OFF or the motor get the power supply. There are two relay system used to change the direction of rotation easily through microcontroller. ${ }^{11,12}$

Table I Parts of the Components

\begin{tabular}{lll}
\hline S.No & Name of the components & Ratings \\
\hline I & PMDC motor & 250watts \\
2 & battery & I2V, I5ah -2 No's \\
3 & MCB & I5amps \\
4 & Arduino microcontroller & I No \\
5 & Accelerator Sensor & I No \\
6 & Battery charger & I No \\
7 & Wheelchair & I No \\
8 & Total cost of the system & I8,000 \\
\hline
\end{tabular}

The micro controller gets the inputs from sensor. In the proposed system, hand moment sensor is used to get the input signal and produce or pass the commend to the actuator or relay system. When hand moment is in upward direction then it moves on forward direction. Similarly, when hand movement is in downward direction, the motor operates reverse direction.

\section{Process of methodology}

Arduino open source micro controller board system is used to program the controller. In that program details are mentioned above the movement of forward and reverse direction. When signal is one or gloves up-direction, it moves or operate the vehicle on one direction or Forward motion. When signal was changed, it moves another direction. It was executed through change of the power supply flow to the PMDC motor. For example, during forward rotation motor positive 
terminal connected to battery positive terminal point, similarly motor negative terminal connected to battery negative power supply point. In this condition motor moves forward direction, when the power supply changes through relay coil two. The motor direction changed into opposite direction that means reverse direction. Microcontroller is designed with two programs, one for relay and another one based on operating system. During the time relay 2 was in operative. When relay 2 starts to operate at that time relay 1 was inoperative.

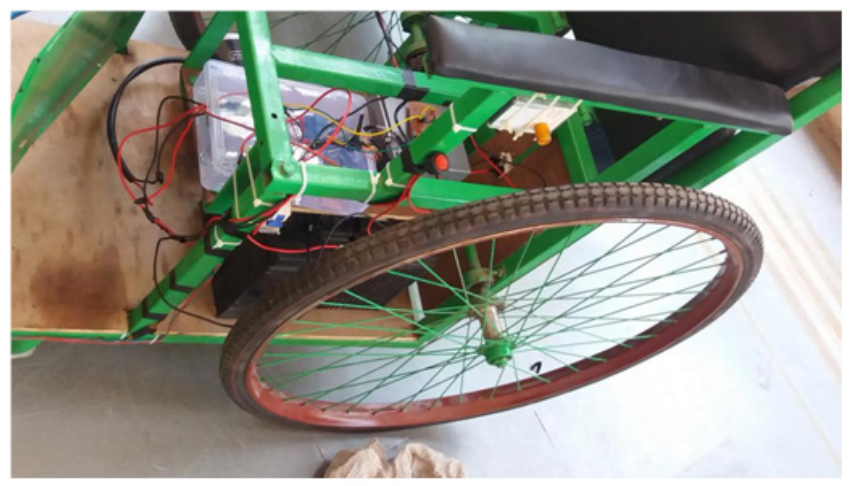

Figure I Right Side view of the vehicle with switch arrangement.

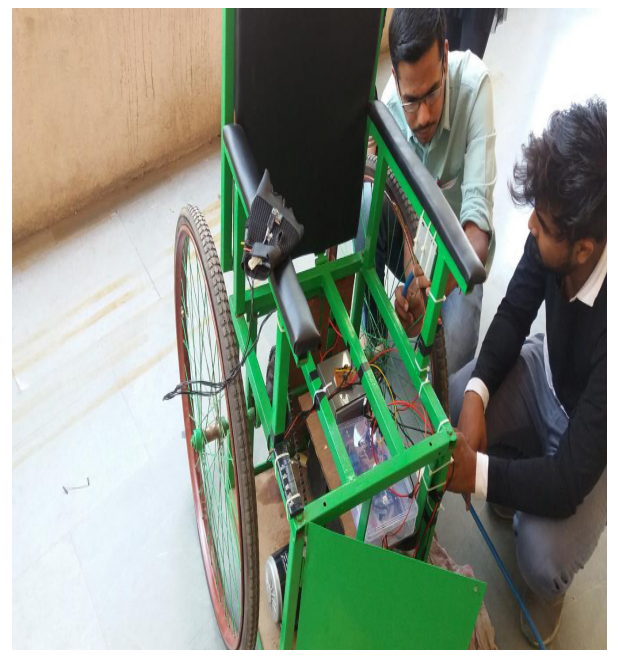

Figure 2 Left Side view of the vehicle with sensor arrangement.

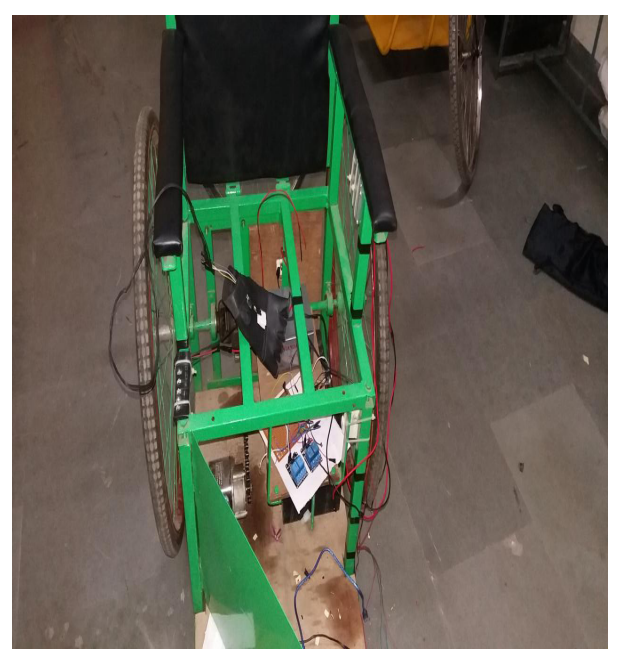

Figure 3 Complete setup of the proposed system.

\section{Analysis of technique}

The proposed system consists of the following major components. Such as 250 watts PMDC, $24 \mathrm{~V}$ and $15 \mathrm{AH}$ Battery, MCB, Microcontroller, sensor, battery charger, 24volts and $15 \mathrm{amps}$ relay board contains two relays. These relay board connected through optocoupler. These optocoupler act as isolation or mediator between higher voltage of motor and lower voltage side of micro controller.

It is particularly important about the connection of relay board. The relay board consists of three major terminals such as common, normally closed, and normally open. These normally close connection operates without power supply or before energizing the relay coil. Once relay coil energizes the common connected to normally open point.

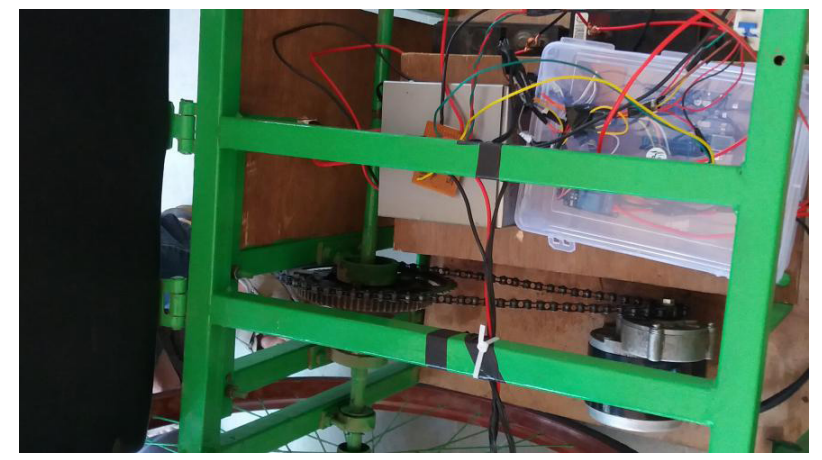

Figure 4 Close view of the Gear arrangement and electronics items.

\section{Results and discussion}

The output of this proposed automatic wheelchair for physically challenged people was working well. It does not require any other people's support to move freely one place to another place. The proposed system was more helpful for those who expected to travel alone as patient and physically challenged people. The proposed consists of two relay circuit. Relay circuit one used to rotate the vehicle on forward direction, the second relay coil used to operate the vehicle on reverse direction. Proper connection should be needed to avoid the short circuit of the battery power supply. When connection is wrong, immediately the board get damage, I.e. the relay get failure. It will operate on ten to fifteen kilometer per hour because of connecting with 250 watts permanent magnet DC motor. This speed was incredibly good for traveling inside the room and corridor. It does not contain any starting arrangement, so people freely operate the vehicle based on their convenient. In addition, there is one variable switch is called as variac. The variac uses to control the speed of the motor, based on the patient require, it can change the speed. I.e. it is act as gear system, stage of gear one, two, three similar fan regulators.

Evaluation of the proposed system was incredibly good during off running. It will operate without making any noise as well as pollutionfree environment. It is user flexible, drive to operate noise free operation as well smooth operation. It will operate more than $40 \mathrm{kms}$ for single time of charge because it connected with two $12 \mathrm{~V}$, $15 \mathrm{AH}$ battery system.

\section{Conclusion and future enhancement}

The proposed system helps to solve the exciting Problem faced by the physically challenged people, old age people, and patient, etc. Physically challenged people need someone helps always move from one place to another place. The exciting solution of proposed problem is wheel chair arrangement, walk stick etc. but the major drawback of 
these exciting product solution is requiring by someone, helper may be nurse, or ward boy, or anyone relative assistance. Without help of someone the patient cannot move from one place to another place. It is depended nature. In the Proposed method uses to solve by the exciting problem was automatic moving wheelchair arrangement, these wheelchair does not require any other support. The wheelchair operation is like electric vehicle operation. In that wheels related to Permanent Magnet Direct Current (PMDC) motor and battery operating system. The benefits of the proposed system include, it does not contain neither accelerator not steering arrangement. So, the system operation is based on hand gloves, based on the hand gloves position the wheelchair move front or back side. The extension of the proposed system is operated by combination of joystick and remote control. The remote control may be the combination of app and IR remote control system. The proposed research will do speed control of vehicle and battery charging system. In future, Internet-of-things (IOT) uses to communicate the vehicle place, battery level to the closet person. In addition to this connected solar photo voltaic system on chair back side to get the continuous power during daytime as well charge the battery.

\section{Funding}

None.

\section{Acknowledgements}

Author would like to thank the Sanjivani college of engineering for providing facility to enrich knowledge.

\section{Conflicts of interest}

The author declares that there was no conflict of interest.

\section{References}

1. Arulmurugan R. Transformerless H-bridge inverter based PV system for harmonic current compensation. Journal of Electrical Engineering. 2018:1-8.

2. Rajendran R, Sathiyavani R, Balakrishnan R, et al. An Overview of Microprocessor control of Inverter. International Journal of Engineering \& Technology. 2018;7(3.24):532-535.
3. Arulmurugan R. Analysis of Fuzzy-Logic MPPT Controller for Photovoltaic Application. Journal of Alternative and Renewable Energy Source. 2018;4(3):1-15.

4. Arulmurugan R. Photovoltaic powered transformer less hybrid converter with active filter for harmonic and reactive power compensation. ECTI Transactions on Electrical Engineering, Electronics, and Communications. 2018;16(2):44-51.

5. Arulmurugan R, Rajender B, Sathyavani B, et al. An Overview of Converters and Inverters. International Journal of Engineering \& Technology-UAE. 2018;7(3):992-994.

6. Sathyavani B, Balakrishna K, Arulmurugan R, et al. Highly Efficient and Reliable Inverter Concept topology with Matlab Simulation towards the Safety Requirement of Leakage Currents. International Journal of Engineering \& Technology-UAE. 2018;7(3):998-1000.

7. Arulmurugan R, Monika P. A simulation analysis of PV powered IncCond MPPT based transformer less hybrid active filter for power quality improvement. 2017;6(4).

8. Arulmurugan R. Comparative evaluation of new FLC controller based MPPT for a DC to DC buck-boost zeta converter. WSEAS Transactions on power systems. 2016;11:27-34.

9. Arulmurugan R, Venkatesan T. Research and Experimental Implementation of a CV-FOINC Algorithm Using MPPT for PV Power System. Journal of Electrical Engineering and Technology. 2015;10(4):1389-1399.

10. Arulmurugan R. Design and testing of stability improvement of nine multi-level H-inverter for distribution system. International Journal of Robotics and Automation. 2019;8(4):245-255.

11. Petry MR, Moreira AP, Faria BM, et al. IntellWheels: Intelligent wheelchair with user-centered design. 2013 IEEE 15th International Conference on e-Health Networking, Applications and Services (Healthcom 2013). 2013:414-418.

12. Faria BM, Reis LP, Lau N. A Survey on Intelligent Wheelchair Prototypes and Simulators. New Perspectives in Information Systems and Technologies. 2014;1:547-557. 